\title{
A STUDY ON THE GROUND STATES STRUCTURE OF EVEN-EVEN ${ }^{104-106} R u$ ISOTOPES
}

\author{
I. Hossain ${ }^{1 *}$ Huda H. Kassim ${ }^{2}$, Fadhil I. Sharrad ${ }^{2}$, Mushtaq A. Al-Jubbori ${ }^{3}$, \\ A. Salam ${ }^{4}$, M. Saleem ${ }^{5}$ \\ ${ }^{1}$ Department of Physics, Rabigh college of Science and Arts, 21911 Rabigh, King Abdulaziz University, \\ Jeddah, Saudi Arabia; \\ ${ }^{2}$ Department of Physics, College of Science, Kerbala University, 56001 Karbala, Iraq; \\ ${ }^{3}$ Department of Physics, College of Education for Pure Science, University of Mosul, 41001 Mosul, Iraq; \\ ${ }^{4}$ Department of chemistry, Rabigh college of Science and Arts, 21911 Rabigh, King Abdulaziz University, \\ Jeddah, Saudi Arabia; \\ ${ }^{5}$ Department of Industrial Engineering, Faculty of Engineering-Rabigh, King Abdulaziz University, \\ Saudi Arabia
}

(Received May 6, 2019)

\begin{abstract}
In this paper, even-even ${ }^{104-106} R u$ isotopes have been studied the ground state bands using Matlab computer code (IBM-1.Mat). We apply the interacting boson model-1 (IBM-1) formula for $O(6)$ symmetry in $R u$ isotopes with neutron $N=60,62$. The theoretical energy levels up to spin-parity $12^{+}$have been obtained for ${ }^{104-106} R u$ isotopes. The yrast states, gamma band, beta band, and $B(E 2)$ values are calculated for these nuclei. The published experimental and calculated $R 4 / 2$ values indicate that the even-even ${ }^{104-106} R u$ isotopes have $O(6)$ dynamic symmetry. The present results have been compared to the published experimental data and are found good harmony with each other. The outcome of our investigation of the potential energy surfaces (PES) of both isotopes belonging to $O(6)$ character.
\end{abstract}

PACS: 21.10.-k;42.40.Ht; 42.30.Kq

\section{INTRODUCTION}

Recently Ruthenium isotope has been a focus of the nuclear structure of many theoretical and experimental investigations. The low-lying even nuclei had been successfully explained nuclear collective characters using IBM-1[1]. In the first beginning the collective states can be describes by a system of identical bosons $N_{B}$. These are S-boson $(L=0)$ and $d$-boson $(L=2)$. There is no discrepancy between neutron and proton in IBM-1. There are three dynamical symmetries indicated by $U(5)$ analogous to spherical vibrator, $S U(3)$ deformed rotor and $O(6) \gamma$-soft. The microscopic a harmonic vibrator approach (MAVA) used in investigating the lower level collective states in Ruthenium isotopes [2].

The Ruthenium isotopes have atomic number $Z=44$. It belongs near to closed shell $S n$ (magic number $Z=50)$. The external forms of even ${ }^{104-106} R u$ isotopes have $\pi g_{9 / 2}^{-6}$ (6 proton holes) and $\nu g_{9 / 2}^{10,12}$ (10 and 12 neutron particles) close to magic number 50. This configuration has been investigated the ground state structure from spherical to deformed symmetry. The edifice of yrast levels and electromagnetic strength of $R u$ isotopes were studied by many scientists [3-7].
Recently, the properties of the yrast level were studied in $P d$ isotopes with even neutron $N=54 \ldots 64$ [8]. The electromagnetic reduced transition strength of $C d$ isotopes with $N=66 \ldots 74$ were investigated [9]. The $B(E 2)$ value of yrast band of even ${ }^{102-112} P d$ and ${ }^{96-102} R u$ isotopes were investigated by IBM-1[10,11]. The lower level of ${ }^{184} \mathrm{~W}$ and ${ }^{184} \mathrm{Os}$ nuclei were investigated [12].

The present aim particularly focuses the structure of the yrast band, gamma band and beta band, electromagnetic transition and the potential energy surfaces to find the dynamical symmetry of even ${ }^{104-106} R u$ isotopes by the application of IBM.

\section{METHODOLOGY}

The Interacting Boson Model (IBM) gives occupation to truncated model space for nuclei with $N$ number of nucleons. It provides a quantitative description of indistinguishable particles with forming pairs of $L=0$ and 2. The Hamiltonian of IBM-1[13] is given

$$
H=\Sigma_{i=1}^{N} \varepsilon_{i}+\Sigma_{i<j}^{N} V_{i j}
$$

where $\varepsilon_{i}$ indicates energy of boson, $V_{i j}$ indicates potential energy of boson between $i$ and $j$. Hamiltonian

*Corresponding author E-mail address: mihossain@kau.edu.sa 
is given from multi-pole form [14]

$$
\begin{aligned}
\hat{H} & =\varepsilon \hat{n}_{d}+\alpha_{0} \hat{P} \cdot \hat{P}+\alpha_{1} \hat{L} \cdot \hat{L}+\alpha_{2} \hat{Q} \cdot \hat{Q}+ \\
& +\alpha_{3} \hat{T}_{3} \cdot \hat{T}_{3}+\alpha_{4} \hat{T}_{4} \cdot \hat{T}_{4},
\end{aligned}
$$

where

$$
\begin{aligned}
& \hat{n}_{d}=\left(d^{+}, \tilde{d}\right), \quad \hat{P}=\frac{1}{2}(\tilde{d} . \tilde{d})-\frac{1}{2}(\tilde{s} . \tilde{s}), \\
& \hat{L}=\sqrt{10}\left[d^{+} \times \tilde{d}\right]^{(1)}, \\
& \hat{Q}=\left[d^{+} \times \tilde{s}+s^{+} \times \tilde{d}\right]^{(2)}-\frac{\sqrt{7}}{2}\left[d^{+} \times \tilde{d}\right]^{(2)}, \\
& \hat{T}_{3}=\left[d^{+} \times \tilde{d}\right]^{(3)}, \quad \hat{T}_{4}=\left[d^{+} \times \tilde{d}\right]^{(4)} .
\end{aligned}
$$

Here $\hat{P}$ (the pairing operator), $\hat{Q}$ (quadrupole operator), ( number of $\hat{n}_{d}$ boson), $\hat{L}$ (operator of angular momentum), and $\hat{T}_{3}$ (octupole operators), and $\hat{T}_{4}$ (hexadecapole operators).

The Hamiltonian starting with $U(6)$ and complete with group $O(2)$ as given in Eq.(2) is bringing to a lower state of three limits, gamma-soft $O(6)$, vibration $U(5)$ and rotational $S U(3)$ nuclei [15]. It is known that the limit in the $O(6), S U(3)$ and $U(5)$ the parameters are $\alpha_{0}, \alpha_{2}$, and $\varepsilon$ respectively.

The Hamiltonian and eigen-values for the three limits [16]:

$$
\begin{aligned}
& U(5): \\
& \quad \hat{H}_{U(5)}=\varepsilon \hat{n}_{d}+\alpha_{1} \hat{L} \cdot \hat{L}+\alpha_{3} \hat{T}_{3} \cdot \hat{T}_{3}+\alpha_{4} \hat{T}_{4} \cdot \hat{T}_{4}, \\
& \quad E\left(n_{d}, \sigma, L\right)=\varepsilon n_{d}+K_{1} n_{d}\left(n_{d}+4\right)+ \\
& +K_{4} \sigma(\sigma+3)+K_{5} L(L+1),
\end{aligned}
$$

with

$$
\begin{aligned}
& K_{1}=1 / 12 a_{1}, \\
& K_{4}=-1 / 10 a_{1}+1 / 7 a_{3}-3 / 70 a_{4}, \\
& K_{5}=-1 / 14 a_{3}+1 / 14 a_{4} .
\end{aligned}
$$

$O(6)$ :

$$
\begin{aligned}
& \hat{H}_{O(6)}=\alpha_{0} \hat{P} \cdot \hat{P}+\alpha_{1} \hat{L} \cdot \hat{L}+\alpha_{3} \hat{T}_{3} \cdot \hat{T}_{3}, \\
& E(\sigma, \nu, L)=K_{3}[N(N+4)-\sigma(\sigma+4)]+ \\
& +K_{4} \nu(\nu+3)+K_{5} L(L+1),
\end{aligned}
$$

with

$$
\begin{aligned}
& K_{1}=1 / 4 a_{0}, \\
& K_{4}=1 / 2 a_{3}, \\
& K_{5}=-1 / 10 a_{3}+a_{1} .
\end{aligned}
$$

$S U(3)$ :

$$
\begin{aligned}
& \hat{H}_{S U(3)}=\alpha_{1} \hat{L} \cdot \hat{L}+\alpha_{2} \hat{Q} \cdot \hat{Q} \\
& E(\lambda, \mu, L)=K_{2}\left[\lambda^{2}+\mu^{2}+\lambda \mu+3(\lambda+\mu)\right]+ \\
& +K_{5} L(L+1)
\end{aligned}
$$

with

$$
\begin{aligned}
& K_{2}=1 / 2 a_{2}, \\
& K_{5}=a_{1}-3 / 8 a_{2} .
\end{aligned}
$$

$K_{1}, K_{2}, K_{3}, K_{4}$, and $K_{5}$ are other strength parameters.

Then applying particular limit of symmetry $(O(6), S U(3), U(5))$ to determine the frame of a set of nuclei is more advantageous than full Hamiltonian of IBM-1. It comprise multi-free parameters those make it simple to fit the structure of a nuclei.

\section{RESULTS AND DISCUSSION}

The obtained results can be discussed for yrast state, $\gamma$-band, $\beta$-band, effective charge, transition probabilities $B(E 2)$, maxing ratio and potential energy surfaces. The calculations were done by IBM-1.

The $\gamma$-unstable limit has applied for ${ }^{104,106} R u$ nuclei using published data of energy ratios $\left(E_{2}: E_{4}\right.$ : $\left.E_{6}: E_{8}=1: 2.5: 4.5: 6.5\right)$. In the IBM-1, the even ${ }^{104,106} R u$ nuclei have 3 proton boson holes and 5 and 6 neutron boson particle respectively. Therefore total bosons numbers of ${ }^{104} R u$ and ${ }^{106} R u$ nuclei are 8 and 9 , respectively. The IBM- 1 models carry out with no difference between the bosons of proton and neutron. The energy ratio $R=E 4_{1}^{+} / E 2_{1}^{+}$gives the information of the symmetry shapes of a nucleus. The symbol $E 2_{1}^{+}$and $E 4_{1}^{+}$are at energy level $2_{1}^{+}$and $4_{1}^{+}$ respectively. It is known that the $R=E 4_{1}^{+} / E 2_{1}^{+} \approx 2$ is for $U(5), R=E 4_{1}^{+} / E 2_{1}^{+} \approx 2.5$ is for $O(6)$ and $R=E 4_{1}^{+} / E 2_{1}^{+} \approx 3.33$ for $S U(3)[17,18]$. The experimental $R_{4 / 2}$ of ${ }^{104} R u$ and ${ }^{106} R u$ isotopes is 2.48 and 2.60 , respectively. In Fig. 1 shows $R_{4 / 2}$ values and found $O(6)$ symmetry in ${ }^{104} R u$ and ${ }_{106} R u$ isotopes.

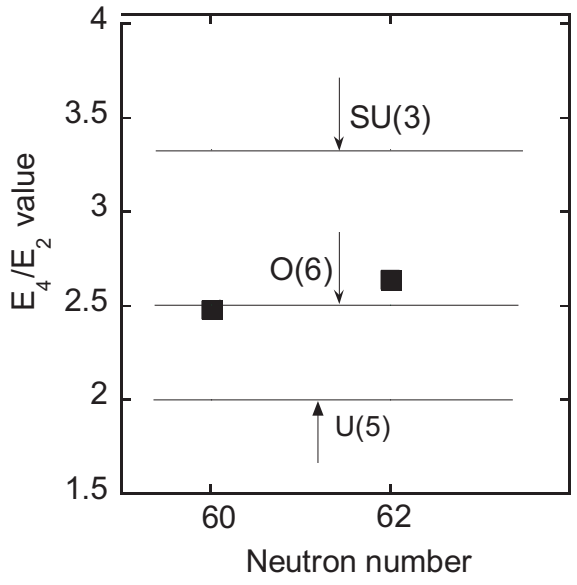

Fig.1. The arrows indicate the $U(5), O(6)$ and $S U(3)$ limits. The $E\left(4_{1}^{-}\right) / E\left(2_{1}^{-}\right)$values of experimental data [22] of the ${ }^{104,106} R u$ isotopes are presented as function of neutrons

The best fit was taken up to $12^{+}$of $R u$ isotopes with neutron $N=60,62$. The parameters were determined the experimental eigen values $\left(E\left(n_{d}, \sigma, L\right)\right)$ from the equation (4). Where $n_{d}, \sigma$, and $L$ are quantum numbers. The parameters are shown in Table 1. 
Table 1. Adopted values of parameters used for IBM-1 calculations. All parameters are given in $M e V$, excepted $N$ and $C H Q$

\begin{tabular}{|c|c|c|c|c|c|c|c|c|}
\hline$A$ & $N$ & $\varepsilon$ & $a_{0}$ & $a_{1}$ & $a_{2}$ & $a_{3}$ & $a_{4}$ & $C H Q(\chi)$ \\
\hline${ }^{104} R u$ & 8 & 0.000 & 0.1098 & 0.0180 & 0.000 & 0.1770 & 0.000 & 0.000 \\
${ }^{106} R u$ & 9 & 0.000 & 0.0990 & 0.0102 & 0.000 & 0.1513 & 0.000 & 0.000 \\
\hline
\end{tabular}

The calculated energy levels as well as experimental data are presented in Table 2. According to the weight of fitting the $R u-104$ and $R u-106$ nuclei are good candidates of $O(6)$ symmetry.

Table 2. g-band (in MeV) for even ${ }^{104-106} R u$ nuclei

\begin{tabular}{|c|c|c|c|c|}
\hline \multirow{2}{*}{$J^{*}$} & IBM & Exp. & IBM & Exp. \\
\cline { 2 - 5 } & \multicolumn{2}{|c|}{$104 R u$} & \multicolumn{2}{|c|}{$106 R u$} \\
\multicolumn{2}{|c|}{} & & \multicolumn{2}{c|}{} \\
\hline & & & & \\
$0^{+}$ & 0.000 & 0.000 & 0.000 & 0.000 \\
$2^{+}$ & 0.3558 & 0.3580 & 0.2726 & 0.2700 \\
$4^{+}$ & 0.8910 & 0.8884 & 0.6570 & $0.7147^{*}$ \\
$6^{+}$ & 1.6056 & 1.5564 & 1.1532 & $1.2958^{*}$ \\
$8^{+}$ & 2.4996 & 2.3204 & 1.7612 & $1.9734^{*}$ \\
$10^{+}$ & 3.5730 & 3.1119 & 2.4810 & 2.7050 \\
$12^{+}$ & 4.8258 & - & 3.3126 & $3.4500^{*}$ \\
& & & & \\
\hline
\end{tabular}

The present data of $\gamma$-bands and $\beta$-bands are presented in Tables 3 and 4 and they are compared with published measured data. From the tables, the IBM calculations and experimental results are in good agreements [19].

Table 3. $\gamma$-band (in $M e V$ ) for even ${ }^{104-106} R u$ nuclei

\begin{tabular}{|c|c|c|c|c|}
\hline \multirow{2}{*}{$J^{*}$} & IBM & Exp. & IBM & Exp. \\
\cline { 2 - 5 } & \multicolumn{2}{|c|}{$104 R u$} & \multicolumn{2}{c|}{$106 R u$} \\
\hline & \multicolumn{2}{|c|}{$R$. } & \multicolumn{2}{c|}{} \\
\hline $2^{+}$ & 0.8868 & 0.8931 & 0.7256 & 0.7923 \\
$3^{+}$ & 1.5966 & 1.2424 & 1.2610 & $1.0915^{*}$ \\
$4^{+}$ & 1.5990 & 1.5026 & 1.3002 & $1.3068^{*}$ \\
$5^{+}$ & 2.4870 & $1.8723^{*}$ & 1.9082 & $1.6411^{*}$ \\
$6^{+}$ & 2.4906 & $2.1966^{*}$ & 1.9670 & $1.9078^{*}$ \\
$7^{+}$ & 3.5568 & - & 2.6672 & $2.2841^{*}$ \\
$8^{+}$ & 3.4878 & - & 2.7456 & $2.9600^{*}$ \\
$9^{+}$ & 4.8060 & - & 3.6360 & - \\
& & & & \\
\hline
\end{tabular}

Table 4. $\beta$-band (in MeV) for even ${ }^{104-106} R u$ nuclei

\begin{tabular}{|c|c|c|c|c|}
\hline \multirow{2}{*}{$J^{\pi}$} & IBM & Exp. & IBM & Exp. \\
\hline & \multicolumn{2}{|c|}{${ }^{104} R u$} & \multicolumn{2}{|c|}{${ }^{106} R u$} \\
\hline $0^{+}$ & 0.9882 & 0.9882 & 0.9900 & 0.9906 \\
\hline $2^{+}$ & 1.3440 & 1.5154 & 1.2626 & 1.3922 \\
\hline $4^{+}$ & 1.8792 & 2.0808 & 1.6470 & - \\
\hline $6^{+}$ & 2.5938 & - & 2.1432 & - \\
\hline $8^{+}$ & 3.5616 & - & 2.7512 & - \\
\hline $10^{+}$ & 4.8120 & - & 3.5380 & - \\
\hline
\end{tabular}

The reduced electric transition probabilities give the more properties on the structure of nuclei. It is known that the $E 2$ transition operator must be a Hermitian tensor of rank two; consequently, the number of bosons must be conserved.

$$
T^{E 2}=\alpha_{2}\left[d^{+} s+s^{+} d\right]^{(2)}+\beta_{2}\left[d^{+} d\right]^{(2)},
$$

where $\left(s^{+}, d^{+}\right)$are creation and $(s, d)$ are annihilation operators for bosons $s$ and $d$. TE2 is the operator of reduced matrix elements of the $E 2 . \alpha_{2}$ is indicated the effective quadrupole charge and $\beta_{2}$ is dimensionless coefficient, $\beta_{2}=\chi \alpha_{2}$.

$$
B\left(E 2, J_{i} \rightarrow J_{f}\right)=\frac{1}{2 J_{i}+1}\left|\left\langle J_{f}\left\|T^{E 2}\right\| J_{i}\right\rangle\right|^{2} .
$$

The parameters, $\alpha_{2}$ and $\beta_{2}$ of Eq.(6), accommodated suitably a set to reproduce the published $B\left(E 2 ; 2_{1}^{+} \rightarrow 0_{1}^{+}\right)$. The effective charge $\left(e_{B}\right)$ in present calculation is shown in Table 5. The values of $e_{B}$ were estimated to reproduce experimentally $\left(B\left(E 2 ; 2_{1}^{+} \rightarrow 0_{1}^{+}\right)\right)$.

Table 5. Effective charge for even ${ }^{104-106}$ Ru nuclei

\begin{tabular}{|c|c|c|}
\hline $\mathrm{A}$ & $\mathrm{N}$ & $e_{B}(e b)$ \\
\hline${ }^{104} R u$ & 8 & 0.0935 \\
${ }^{106} R u$ & 9 & 0.0916 \\
\hline
\end{tabular}


The values $\beta_{2}=0$ for ${ }^{104,106} R u$ isotopes because these nuclei have the $O(6)$ property. The values of $B(E 2)$ data are presented in Table 6 for $R u$ isotopes with neutron $N=60,62$ in this study [19]. The calculated data of IBM-1 is good agreements with the available published experimental results.

Table 6. The $B(E 2)$ value (in $\left.e^{2} b^{2}\right)$ of even ${ }^{104-106} \mathrm{Ru}$ isotopes

\begin{tabular}{|c|c|c|c|c|}
\hline \multirow{2}{*}{$J_{i} \rightarrow J_{f}$} & IBM & Exp. & IBM & Exp. \\
\hline & \multicolumn{2}{|c|}{${ }^{104} R u$} & \multicolumn{2}{|c|}{${ }^{106} R u$} \\
\hline $2_{1}^{+} \rightarrow 0_{1}^{+}$ & 0.1679 & 0.1682 & 0.1966 & 0.1966 \\
\hline $4_{1}^{+} \rightarrow 2_{1}^{+}$ & 0.2273 & 0.2149 & 0.2689 & - \\
\hline $4_{2}^{+} \rightarrow 2_{2}^{+}$ & 0.1282 & - & 0.1541 & - \\
\hline $6_{1}^{+} \rightarrow 4_{1}^{+}$ & 0.2448 & - & 0.2941 & - \\
\hline $6_{2}^{+} \rightarrow 4_{2}^{+}$ & 0.1626 & - & 0.2000 & - \\
\hline $8_{1}^{+} \rightarrow 6_{1}^{+}$ & 0.2384 & - & 0.2934 & - \\
\hline $10_{1}^{+} \rightarrow 8_{1}^{+}$ & 0.2152 & - & 0.2747 & - \\
\hline $10_{2}^{+} \rightarrow 8_{2}^{+}$ & 0.0941 & - & 0.0000 & - \\
\hline $2_{2}^{+} \rightarrow 2_{1}^{+}$ & 0.2273 & 0.1957 & 0.2689 & - \\
\hline $4_{2}^{+} \rightarrow 4_{1}^{+}$ & 0.1166 & - & 0.1401 & - \\
\hline $6_{2}^{+} \rightarrow 6_{1}^{+}$ & 0.0759 & - & 0.0933 & - \\
\hline $8_{2}^{+} \rightarrow 8_{1}^{+}$ & 0.0000 & - & 0.0659 & - \\
\hline
\end{tabular}

The application of potential energy surface (PES) gives the information to find microscopic and geometric shapes such as spherical, prolate, oblate and $\gamma$-independent $(\gamma$-soft $))$. It gives us about symmetry, the shape of nuclei, the minimum deepness and the change of the shape. The PES plots using Skyrme mean field method was drawn by IBM Hamiltonian [20-23]. The state is a product of the boson creation operators $b_{c}^{+}$with

$$
\begin{gathered}
|N, \beta, \gamma\rangle=\frac{1}{\sqrt{N !}}\left(b_{c}^{+}\right)^{N}|0\rangle, \\
b_{c}^{+}=\left(1+\beta^{2}\right)^{-1_{2}}\left\{s^{+}+\beta\left[\cos \gamma\left(d_{0}^{+}\right)+\right.\right. \\
\left.\left.+\sqrt{1 / 2} \sin \gamma\left(d_{2}^{+}+d_{-2}^{+}\right)\right]\right\} .
\end{gathered}
$$

The energy surface as a function of $\beta$ and $\gamma$, has been given [1]

$$
\begin{aligned}
& E(N, \beta, \gamma)= \\
& \quad=\frac{N \varepsilon_{d} \beta^{2}}{\left(1+\beta^{2}\right)+\frac{N(N-1)}{\left(1+\beta^{2}\right)^{2}\left(\alpha_{1} \beta^{4}+\alpha_{2} \beta^{3} \cos 3 \gamma+\alpha_{3} \beta^{2}+\alpha_{4}\right)}} .
\end{aligned}
$$

Here the $\alpha_{i}$ 's are related to the Casimir coefficients $C_{L}, \nu_{2}, \nu_{0}, u_{2}$ and $u_{0} . \beta$ were indicated the total deformation of a nucleus. Then, we can re-write equation (10) for $O(6)$ limit [19]. Fig.2 shows the contour plots in the $\gamma-\beta$ plane resulting from $E(N, \beta, \gamma)$ for ${ }^{104} R u$ and ${ }^{106} R u$ isotopes. The color lines show the values of the potential energy surface in $M e V$. The potential surfaces are approximately independent of gamma only. The mapped IBM energy surfaces of ${ }^{104} R u$ and ${ }^{106} R u$ are $O(6)$ character.
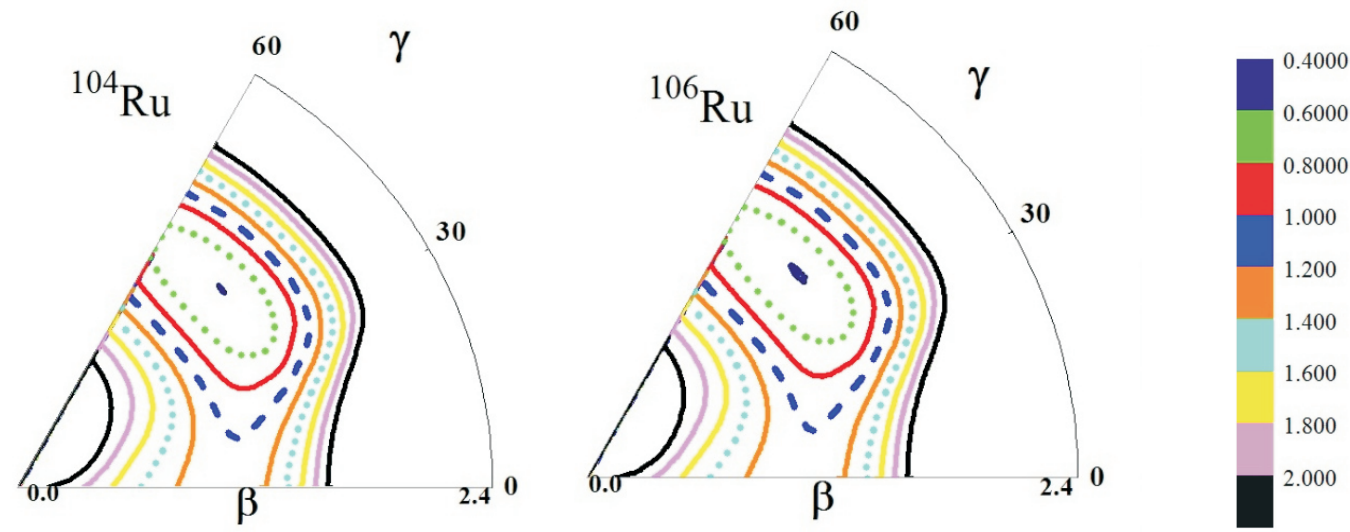

Fig.2. Contour map of potential energy surfaces for Ru isotopes with $N=60,62$

\section{CONCLUSIONS}

The yrast band, gamma band and beta band, electromagnetic transition and potential energy surface of ${ }^{104} R u$ and ${ }^{106} R u$ isotopes have been calculated in term of $O(6)$ limit of IBM-1. The levels up to $12^{+}$of ${ }^{104,106} \mathrm{Ru}$ nucleus are found by the Hamilto- nian of IBM-1. The analyses of the IBM-1 results suggest a satisfactory agreement with the published experimental data. It is established that interacting boson approximations for ${ }^{104} R u$ and ${ }^{106} R u$ isotopes are considered as gamma soft $O(6)$ symmetry. 


\section{ACKNOWLEDGMENTS}

This project was funded by the Deanship of Scientific Research (DSR) at King Abdulaziz University, Jeddah, under grant No. G-223-662-37. The authors, therefore, acknowledge with thanks DSR for technical and financial support.

\section{References}

1. F. Iachello, and A. Aritma. The interacting boson model. Cambridge: Cambridge Univ. press, 1987.

2. J. Kotila, J. Suhonen, and D. S. Delion. Low-lying collective states in $R u^{98-106}$ isotopes studied using a microscopic anharmonic vibrator approach //Phys. Rev. 2003, v.C 68, p.054322.

3. X.L.Che, et al. High spin band structure in ${ }^{112}$ Ru // Chin. Phys. Lett. 2004, v.21, p.1904.

4. X. L. Che, et al. Collective band structures in the neutron-rich ${ }^{107,109}$ Ru nuclei // Chin. Phys. Lett. 2006, v.23, p.328.

5. Y.X.Luo, et al. Odd-parity bands of 108,110,112 Ru // Int. J. Mod. Phys. 2009, v.E 18, p.1697-1716.

6. A. Frank, P. V. Isacker, D. D. Warner. Super symmetry in transitional nuclei and its application to the $R u$ and $R h$ isotopes // Phys. Lett. 1997, v.B 197(4), p.474-478.

7. D. Troltenier, J. A. Maruhm, W. Greiner, V.A. Velazquez, P. O. Hess, J. H. Z. Hamilton // Phys. 1991, v.A 338, p.261.

8. I. M. Ahmed, et al. The evolution properties of even-even ${ }^{100-110} \mathrm{Pd}$ nuclei // Int. J. Mod. Phys. v.E 21, p.1250101.

9. H. Y. Abdullah, et al. Electromagnetic reduced transition properties of even- even ${ }^{104-112} C d$ isotopes // Indian J. Phys. 2013, v.87, p.571-575.

10. I. Hossain, M. A. Saeed, N. N. A. M. B. Ghani, H. Sa'adeh, M. Hussein, H. Y. Abdullah. Electromagnetic reduced transition properties of the ground state band of even-even ${ }^{102-106} \mathrm{Pd}$ isotopes by means of interacting boson model-1 // Indian J. Phys. 2014, v.88, p.5-9.
11. I. Hossain, H. Y. Abdullah, I. M. Ahmed, M. A. Saeed. $B(E 2)$ value of even-even ${ }^{108-112} P d$ isotopes by interacting boson model-1 // Chin. Phys. 2014, v.C 38, p.024104.

12. F. I.Sharrad, I. Hossain, I. M. Ahmed, H. Y. Abdullah, S. T. Ahmad, A.S. Ahmed. $U(5)$ symmetry of even ${ }^{96,98} R u$ isotopes under the framework of interacting boson model (IBM-1) // Braz J Phys. 2015, v.45, p.340-346.

13. L. K. Green. Nuclear structure of 112Cd through studies of decay. M.Sc. thesis. The University of Green, 2009.

14. K. A. Al-Maqtary. IBM-1 Calculations of energy levels and electric transition probabilities $B(E 2)$ in ${ }^{158-160} \mathrm{Gd}$ isotopes // Jordan J. Phys. 2013, v.6, p.95-102.

15. F. Lachello. Nuclear Structure / Edited by K Abraham, K Allaart and A. E. L. Dieperink, New York: Plenum press, 1981.

16. P. V. Isacker. The Interacting Boson Model // Nuclear Structure and Decay Data: Theory and Evaluation workshop, Trieste - Italy, 04 - 15 April, 2005.

17. V. N. Zamfir, R. F. Casten. Proceedings of the Romanian Academy, Series A, 4, 1, 2003.

18. Harish Mohan MITTAL and Vidya DEVI // Turk. J. Phys., 2012, v.36, p.117.

19. B. Richard and Firestone. Table of isotopes (John willey and sons), 1999.

20. R. F. Casten and D. D. Warner. The interacting Boson approximation // Rev. Mod. Phys. 1988, v.60, p.389-469.

21. L. M. Robledo, et al. Role of triaxiality in the ground-state shape of neutron- rich $Y b, H f, W$, $\mathrm{Os}$ and Pt isotopes // J. Phys. G: Nucl. Part. Phys. 2009, v.36, p.115104.

22. K. Nomura, et al. Derivation of IBM Hamiltonian for deformed nuclei // J. Phys.Conf. Ser. 2009, v.267, p.012050.

23. R. F. Casten, N. V. Zamfir. Empirical Realization of a Critical Point Description in Atomic Nuclei // Phys. Lett. 2001, v.87, p.052503. 


\section{ИССЛЕДОВАНИЕ СТРУКТУРЫ ОСНОВНЫХ СОСТОЯНИЙ ЧЕТНО-ЧЕТНЫХ \\ ИЗОТОПОВ ${ }^{104-106} R u$}

I. Hossain, Huda H. Kassim, Fadhil I. Sharrad, Mushtaq A. Al-Jubbori, A.Salam, M.Śaleem

Используя Matlab компьютерный код (IBM-1.Mat), исследовались полосы основных состояний четночетных изотопов ${ }^{104-106} R u$. Мы применили формулу модели-1 взаимодействующих бозонов (IBM-1) для $O(6)$ симметрии $R u$-изотопов для $N=60,62$ нейтронов. Теоретические значения энергетических уровней до значений спин-четности $12^{+}$были получены для изотопов ${ }^{104-106} R u$. Для этих ядер вычислены yrast-состояния, $\gamma$-полосы, $\beta$-полосы и $B(E 2)$-величины. Опубликованные экспериментальные и расчетные величины $R 4 / 2$ показывают, что четно-четные изотопы ${ }^{104-106} R u$ имеют $O(6)$ динамическую симметрию. Эти результаты сравнивались с опубликованными данными экспериментальных исследований, и найдено хорошее согласие между ними. Наши исследования поверхности потенциальной энергии (ППЭ) указывают на $O(6)$ характер обоих изотопов.

\section{ДОСЛІДЖЕННЯ СТРУКТУРИ ГОЛОВНИХ СТАНІВ ПАРНО-ПАРНИХ ІЗОТОПІВ ${ }^{104-106} R u$}

\section{Hossain, Huda H. Kassim, Fadhil I.Sharrad, Mushtaq A. Al-Jubbori, A.Salam, M. Saleem}

Використовуючи Matlab комп'ютерний код (IBM-1.Mat), досліджені полоси основних станів парнопарних ізотопів ${ }^{104-106} R u$. Ми застосували формулу моделі-1 взаємодіючих бозонів (IBM-1) для $O(6)$ симетрії $R u$-ізотопів для $N=60,62$ нейтронів. Теоретичні значення енергетичних рівнів до значень спін-парності $12^{+}$були отримані для ізотопів ${ }^{104-106} R u$. Для цих ядер обчислені yrast-стани, $\gamma$-смуги, $\beta$-смуги та $B(E 2)$-величини. Опубліковані експериментальні та розрахункові величини $R 4 / 2$ показують, що парно-парні ізотопи ${ }^{104-106} R u$ мають $O(6)$ динамічну симетрію. Ці розрахунки порівнювались з опублікованими даними експериментальних досліджень, і знайдено добре узгодження між ними. Наші дослідження поверхні потенціальної енергії (ППЕ) вказуют на $O(6)$ характер обох ізотопів. 